\title{
AVALIAÇÃO E CONTROLE DE ESTOQUE E SUA INFLUÊNCIA NO DESEMPENHO ORGANIZACIONAL: ESTUDO DE CASO EM UMA AUTOPEÇAS
}

\author{
Marlise Fiorentin Vieira \\ Universidade de Caxias do Sul (UCS) \\ Brasil \\ Marta Elisete Ventura da Motta \\ Universidade de Caxias do Sul (UCS) \\ Brasil
}

Alice Munz Fernandes

Universidade Federal do Rio Grande do Sul (UFRGS)

Brasil

Maria Emilia Camargo

Universidade de Caxias do Sul (UCS)

Brasil

Beatriz Lúcia Salvador Bizotto

Universidade de Caxias do Sul (UCS)

Brasil

Data de submissão: 12/12/2017

Data de aceite: $21 / 08 / 2018$

\section{RESUMO}

Este estudo teve por objetivo identificar o custo dos itens de estoque que não possuem movimentação a mais de um ano em uma empresa de autopeças, bem como definir estratégias para sua comercialização. Para tanto, realizou-se uma pesquisa quantitativa, exploratória e descritiva por meio de um estudo de caso, cujo objeto consistiu em uma empresa de comércio varejista de autopeças para caminhões na cidade de Vacaria/RS. Os resultados obtidos demostraram que os itens sem movimentação, em sua maioria importados, acarretaram um desembolso substancial para a empresa. Constatou-se também que o valor dispendido para aquisição do estoque se fosse aplicado em outro investimento de longo prazo representaria maior vantagem financeira.

Palavras-chave: Contabilidade de Custos. Estoques. Autopeças.

\section{ABSTRACT}

This study aimed to identify the cost of inventory items that have not been moved for more than a year in an auto parts company, as well as to define strategies for its commercialization. For that, a quantitative, exploratory and descriptive research was carried out by means of a case study, whose object consisted of a retail company of auto parts for trucks in the city of Vacaria 
/ RS. The results showed that non-moving items, mostly imported, caused a substantial disbursement to the company. It was also found that the amount spent for acquiring the stock if applied in another long-term investment would represent a greater financial advantage.

Keywords: Cost Accounting. Inventory. Autoparts.

\section{INTRODUÇÃO}

A globalização, os avanços tecnológicos e as consequentes modificações econômicas impulsionaram as transformações das rotinas organizacionais, de modo que a busca pela excelência configura-se como objetivo de empresas que estabelecem estratégias para manterem-se no mercado cada vez mais competitivo (PAIVA et al., 1999). Neste contexto, Machado et al. (2015) salientam que o estudo da contabilidade configura-se como impreterível para o desenvolvimento econômico do País, haja vista a geração de emprego e renda.

Segundo Beuren (2009), ao longo dos anos a contabilidade de custos sofreu significativos avanços, sobretudo quanto ao desenvolvimento de distintos sistemas e custos que fornecem subsídios para o processo de tomada de decisão gerencial. Todavia, dentre os componentes de custos das empresas, têm-se o estoque como um dos principais, pois, apesar de ser fundamental para o desenvolvimento da atividade econômica de distintos tipos de empresas, quando indevidamente gerenciado, acarreta custos elevados (CHING, 2000).

Para Callado e Callado (2006, p. 132) “a contabilização de custos é uma necessidade imperiosa para todas as empresas que almejam monitorar escalas de competitividade dentro dos ramos empresariais nos quais atuem". De acordo com Cardoso, Pereira e Guerreiro (2007), no Brasil tem-se intensificado a quantidade de estudos sobre contabilidade de custos, o que se justifica pela multidisciplinariedade de tal tema. Para os autores, a contabilidade de custos passou a despertar a atenção de um número cada vez maior de pesquisadores, que passaram a identificar sua contribuição e relevância em outras áreas.

No que se refere à relevância gerencial de tal tema, Gavioli, Siqueira e Silva (2009) elucidam que a minimização de custos consiste em uma forma emergente de diferenciação, visto que a competitividade impulsiona a adoção de estratégias cada vez mais inovadoras. Neste contexto, os autores salientam que os estoques contribuem significativamente seja para a maximização dos custos ou para ganhos em escala, dependendo da eficiência com que é gerenciado. Para Lima (2003), apesar da melhoria operacional das empresas por meio da minimização nos custos de estoque, estes continuam apresentando criticidade em organizações 
de distintos segmentos econômicos. Assim, no que se refere à comercialização de autopeças, infere-se que tal situação expande-se para este segmento também.

Com base no exposto, a pesquisa realizada teve como objetivo identificar o custo de aquisição dos itens de estoque que não possuem movimentação a mais de um ano em uma empresa de autopeças e definir estratégias para a comercialização destes produtos. Deste modo, além desta introdução, este estudo é composto pelo referencial teórico, que forneceu subsídios para a investigação empírica realizada, em seguida, os procedimentos metodológicos. Posteriormente, apresentam-se e discutem-se os resultados obtidos e, por fim, expõem-se as considerações finais, que contemplam as limitações do estudo e sugestões para pesquisas futuras.

\section{REFERENCIAL TEÓRICO}

\subsection{CONTABILIDADE DE CUSTOS}

De acordo com Neves e Viceconti (2003), a contabilidade de custos surgiu a partir da avaliação de estoque em empresas industriais, visto sua complexidade em relação a empresas comerciais. Os autores salientam que as atividades relacionados aos pagamentos de fatores produtivos, como por exemplo, salários e aquisição de matérias-primas, configuravam-se como elementos principais desse tipo de contabilidade.

Segundo Leone (2008), não é possível criar apenas um objetivo para definir a contabilidade de custos, tendo em vista que consiste em uma área ampla e que cada empresa utiliza as informações para a obtenção de lucro por meio dos registros convencionais. Para Santos et al. (2006) a contabilidade de custos tinha como função inicial fornecer elementos para avaliação dos estoques e apuração do resultado. Todavia, segundo o autor, nas últimas décadas, passou a prestar duas funções importantes na contabilidade gerencial, quais sejam: utilização dos dados de custos para auxílio ao controle e para a tomada de decisões.

Contabilidade de custos é uma atividade que se assemelha a um centro processador de informações, que recebe (ou obtém) dados, acumula-os de forma organizada, analisa-os e interpreta-os, produzindo informações de custos para os diversos níveis gerenciais. Assim, a contabilidade de custos utiliza-se de dados operacionais de distintos tipos, como por exemplo, dados históricos, estimados, padronizados e produzidos. Deste modo, a contabilidade de custos fornece informações diferentes para atender distintas necessidades de gestão (LEONE, 2008). 


\subsection{CUSTO}

De acordo com Wernke (2005), são os gastos efetuados pela empresa que irão beneficiá-la, visto que objetivam um retorno lucrativo no futuro, como por exemplo a aquisição de máquinas e equipamentos, bem como os estoques. Para Dubois, Kulpa e Souza (2006) a empresa deverá avaliar se foram realizados estudos que mostrem as vantagens do investimento já que estes devem trazer o retorno esperado após sua ocorrência.

Para Padoveze (2006) custos são gastos indispensáveis para o desenvolvimento da atividade da empresa, e de um modo geral estão ligados à área industrial. Por sua vez, Stark (2007) elucida que custos consistem em esforços financeiros de uma empresa para produzir bem ou prestar serviço e, desse modo, obter receita. Conforme Martins (2006) os custos são agrupados em diretos e indiretos de acordo com sua participação na produção. Também, segundo o autor, considerando a relação entre o valor do custo e o volume de atividade, são classificados em fixos e variáveis.

Para Crepaldi (2009) os custos diretos podem ser medidos de acordo com a quantidade produzida, não sendo necessários rateios, visto que são alocados diretamente ao produto. Nesse sentido, Wernke (2005) salienta que esse tipo de custo configuram-se como gastos que podem ser apropriados e mensurados às unidades. Em contrapartida, os custos indiretos consistem em gastos que não podem ser alocados diretamente ao produto e devem ser alocados por meio de rateios, alocação ou apropriação (PADOVEZE, 2006). Assim, dependem de cálculos para a obtenção de estimativas, possibilitando a sua alocação (CREPALDI, 2009).

No que se refere a custos fixos, Greco, Gãrtner e Arend (2009) elucidam que estes independem do volume produzido, de modo que seu valor não é afetado. Trata-se de custos que existem mesmo que a empresa não produza unidade nenhuma, ou seja, possuem seu montante fixado, não sendo, portanto regrado pela quantidade produzida (WERNKE, 2005). Por sua vez, os custos variáveis são aqueles que variam de acordo com a quantidade produzida GRECO; GÃRTNER; AREND, 2009), ou seja, conforme a proporção do nível de atividade. Também oscilam conforme o volume de vendas que é proporcional ao seu valor (PADOVEZE, 2006).

\subsection{MÉTODOS DE CUSTEIO}

Métodos de custeio objetivam a coleta de informações para que as empresas tomem decisões gerenciais. Deste modo, a principal diferença entre os métodos tradicionais de custeio consistem na relação da apropriação dos custos fixos (CREPALDI, 2009). O método de custeio 
por absorção consiste na alocação dos custos diretos e indiretos, de modo que os custos variáveis de produção e comercialização oscilam conforme a matéria-prima utilizada e o tipo de tributação, de acordo com a quantidade produzida (WERNKE, 2005). Nesse sentido, Greco, Gãrtner e Arend (2009), elucidam que este método de custeio consideram que a alocação dos custos diretos e indiretos de produção que devem ser absolvidos pelo processo de elaboração. Assim, este método é aceito pela contabilidade, pois é o único que atende os princípios contábeis.

Segundo Stark (2007), este método apropria todos os custos variáveis e fixos. Assim, as despesas que não são ligadas a produção são excluídas do cálculo. Para tanto, o autor define que tal processo é composto por cinco etapas, quais sejam: separação de custos e despesas; apropriação de custos diretos e indiretos no período; apuração do custo da produção acabada; apuração do custo dos produtos vendidos, e; apuração do resultado.

Já o custeio direto ou variável, segundo Stark (2007), utiliza somente os custos fixos equivalentes a atividade, de modo que o valor dos estoques é inferior do que em comparação a utilização do método de custeio por absorção. Segundo o autor, esse método informa a contribuição que representa para a empresa e não o custo do produto. Assim, para elencar-se o valor do custeio, têm-se as seguintes etapas: separação dos custos fixos e variáveis; alocação dos custos variáveis aos produtos; cálculo da Margem de Contribuição (MC) por meio da diferença entre a receita e os custos variáveis; cálculo da MC total através do somatório da MC unitária pela diferença entre os custos fixos. Para Bomfim e Passarelli (2008), o método de custeio variável considera somente os custos e despesas variáveis da empresa, o que, portanto, dispensa rateios e suas consequentes distorções.

Segundo Greco, Gãrtner e Arend (2009), este método somente pode ser utilizado de forma gerencial pois ele fere os princípios contábeis da competência, realização e confrontação. Neste método podemos destacar algumas vantagens, quais sejam: variação do resultado não é afetada uma vez que o lucro líquido não se afeta pela variação nos inventários; facilidade na obtenção da margem de contribuição dos produtos; análise dos produtos que possuem mais margem de contribuição unitária; trata-se de um método aliado na tomada de decisão pois só considera o custo variáveis, e; possibilita realizar a correção do preço de venda praticado pela empresa (STARCK, 2007).

O custeio variável é utilizado para auxiliar o processo de tomada de decisão, porém, não é aceito pela legislação brasileira, pois tende a minimizar a base de cálculo para impostos como o Imposto de Renda da Pessoa Jurídica (IRPJ) e Contribuição Social sobre o Lucro Líquido (CSLL), por exemplo. Esse método apenas considera os custos e despesas variáveis do 
período, excluindo os custos fixos (CREPALDI, 2009).

Segundo Ribeiro (2011), o custeio ABC (Activity-Based Costing, ou custeio baseado em atividades) consiste em um método que leva os custos indiretos aos produtos por meio de atividades. Assim por esse método os custos são melhor distribuídos com uma forma mais justa. Os CIFS devem ser transferidos com base na atividade que o consumiu. O sistema de custeio ABC deve ser dividido na empresa por departamentos ou centro de custos. Assim, o autor elucida que em primeiro momento, os custos são acumulados nos departamentos aonde foram gerados e, posteriormente os custos fixos indiretos são transferidos para as atividades relevantes que os criaram e, por fim, são transferidos para seus respectivos produtos.

Ainda Ribeiro (2011), enfatiza a primeira direção é os custos são transferidos dos departamentos para a atividade é o direcionador um exemplo comum é a agua que serva para consumo e higiene pessoal o custo tem a causa o número de empregados. A segunda direção é os custos são transferidos das atividades para os produtos, neste estágio é indicado como os produtos consomem as atividades. Para Wernke (2005), por deter conhecimento das atividades que realiza, a empresa consegue analisar os custos inerentes a estas, bem como os valores do consumo efetivo ou estimado pelos itens produzidos no período. De acordo com o autor, os custos são distribuídos nas atividades por meio de rateio.

\subsection{ESTOQUE}

Segundo Greco, Gãrtner e Arend (2009), estoque consiste em bens adquiridos para a comercialização ou para o processo de produção. Assim, é definido como bens que objetivam o lucro e representa um dos principais elementos do ativo circulante e, desse modo requere um controle físico, monetário e contábil. Segundo os autores, estoques são bens adquiridos para a revenda sem que seja necessário o processo de transformação ou ainda podem ser armazenados e destinados à venda por meio de fabricação própria (IUDICÍBUS; MARTINS, 2009). A análise para identificar o desbalanceamento do estoque consiste em um parâmetro de relevância funcional superior a observação dos níveis de estoque (ALVES et al., 2008).

Assim, materiais que possuem baixa movimentação, que estão obsoletos ou danificados devem ser considerados como provisão de perdas. Nestes itens se enquadram aqueles que não podem ser utilizados para a produção normal ou que estão fora de especificações. Estes materiais devem ser avaliados por seu valor liquido realizável ou em determinados casos como sucata. Geralmente são cotados por um montante só de acordo com a quantidade para destinar o valor final. Os estoques de baixa rotação com quantidades 
expressivas em relação ao tempo que estão sem movimentação até a venda, independente da aquisição - por meio econômico, garantia de estoque ou compras em grande volume - devem ser classificados como realizável a longo prazo, não gerando nenhuma provisão (IUDICIBUS; MARTINS; GLEBCKE, 2009).

\section{PROCEDIMENTOS METODOLÓGICOS}

A pesquisa realizada configurou-se como quantitativa em relação a sua abordagem, exploratória e descritiva no que se refere a sua finalidade. Como estratégia de investigação, empregou-se estudo de caso único, que segundo Yin (2015) consiste no estudo de um fenômeno considerando o contexto no qual está inserido, cujos os limites entre estes não são claramente definidos. Os dados foram coletados por meio de registros em arquivos e documentos, especificamente, relatórios contábeis e registros fotográficos. Para análise, utilizou-se planilhas eletrônicas a fim de facilitar a realização dos cálculos, bem como gráficos. Assim, o universo da pesquisa consistiu em a parte do estoque obsoleto a mais de um ano em uma empresa do comércio varejista de auto peças para caminhões, totalizando 3.946 itens sem movimentação a mais de um ano, em sua maioria importados, cujo custo de aquisição corresponde a $\mathrm{R} \$$ $814.000,00$.

Esta empresa está situada na cidade de Vacaria - RS e foi fundada na década de 80. Seu regime de tributação corresponde ao lucro presumido e seu quadro funcional é composto por cerca de 21 funcionário distribuídos nos setores de vendas, administrativo e operacional. A falta de movimentação de determinados itens de estoque, deve-se ao fato de peças saírem de linha devido a minimização da demanda. Apesar do Estado do Rio Grande do Sul representar cerca de $70 \%$ das receitas da empresa, esta revende seus produtos para os demais Estados do Brasil e também faz importações e exportações. A mesma dispõe de todas as peças para caminhões pequeno, médio e grande porte, exceto acessórios e pneus, as peças são direcionadas as seguintes marcas de caminhões: Scania, Volvo, Volkswagen, Iveco, Mercedes Bens, Man, Ford Cargo, Darf.

A partir disso, para a realização da análise dos dados, foram escolhidos os 11 (onze) itens sem movimentação a mais de um ano de maior significância, ou seja, que representaram maior desembolso no momento de sua aquisição. Assim, os dados foram coletados por meio de um relatório fornecido pela empresa, que contempla a descrição das peças que compõem o estoque assim como sua data de aquisição e valor. Em seguida realizou-se as uma análise pelos índices do IGP-M e o IPCA-E desde a data da aquisição até o dia 01/06/2016 a fim de corrigir 
monetariamente os valores dos produtos.

Em seguida, comparou-se o valor do custo da aquisição dos produtos em estoque com possível ganho de despendê-lo no investimento CDB -DI, no banco XX até 31/12/2015. Será explorada situação real da empresa perseverando o valor unitário do objeto estudado. Ainda, verificou-se por meio de documentos e registros fotográficos a organização da empresa e a disposição dos produtos. Após análise foi sugerido ao empresário às mudanças que possam trazer a recuperação deste valor que foi desembolsado pela empresa relacionado a itens que não tem o giro.

\section{ANÁLISE E DISCUSSÃo DOS RESULTADOS}

Para análise dos dados, inicialmente realizou-se o levantamento dos 11 (onze) produtos do estoque que foram estudados, conforme demonstra o Quadro 1.

Quadro 1 - Informações base para análise do estudo de caso

\begin{tabular}{|c|c|c|c|c|c|c|}
\hline Descrição & Marca & $\begin{array}{c}\text { Data última } \\
\text { venda }\end{array}$ & $\begin{array}{l}\text { Data última } \\
\text { compra }\end{array}$ & Qtde & Custo & Total \\
\hline $\begin{array}{l}\text { Radiador água P94 } \\
\text { P114 P124 }\end{array}$ & Pacini & Sem registro & $02 / 04 / 2013$ & 1 & $\mathrm{R} \$ 1.150,00$ & $\mathrm{R} \$ 1.150,00$ \\
\hline $\begin{array}{c}\text { Atuador embreagem } \\
\text { Axor Actros }\end{array}$ & Incoparts & Sem registro & $20 / 05 / 2013$ & 1 & $\mathrm{R} \$ 796,49$ & $\mathrm{R} \$ 796,49$ \\
\hline $\begin{array}{c}\text { Grade frontal Iveco } \\
\text { Eurotech }\end{array}$ & Importado & Sem registro & $18 / 09 / 2013$ & 1 & $\mathrm{R} \$ 835,00$ & $\mathrm{R} \$ 835,00$ \\
\hline $\begin{array}{c}\text { Radiador agua CLP } \\
\text { S4 S5 }\end{array}$ & Pacini & $11 / 07 / 2014$ & 07/07/2014 & 2 & $\mathrm{R} \$ 1.137,25$ & $\mathrm{R} \$ 2.274,50$ \\
\hline Porta LE FH & Importado & $26 / 05 / 2015$ & $15 / 07 / 2014$ & 2 & $\mathrm{R} \$ 1.350,00$ & $\mathrm{R} \$ 2.700,00$ \\
\hline $\begin{array}{l}\text { Porta LD Eurotech } \\
\text { Eurocargo } \mathrm{S}\end{array}$ & Amalca & Sem registro & $01 / 09 / 2014$ & 1 & $\mathrm{R} \$ 1.150,99$ & $\mathrm{R} \$ 1.150,99$ \\
\hline Catalizador 114124 & Importado & Sem registro & $07 / 10 / 2014$ & 4 & $\mathrm{R} \$ 704,74$ & $\mathrm{R} \$ 2.818,96$ \\
\hline $\begin{array}{c}\text { Semi eixo LD Iveco } \\
\text { Eurotech }\end{array}$ & Resipeças & Sem registro & $14 / 10 / 2014$ & 1 & $\mathrm{R} \$ 721,71$ & $\mathrm{R} \$ 721,71$ \\
\hline Porta LE Volvo FM & Importado & Sem registro & $20 / 11 / 2014$ & 1 & $\mathrm{R} \$ 1.162,12$ & $\mathrm{R} \$ 1.162,12$ \\
\hline $\begin{array}{c}\text { Suporte aluminio LE } \\
\text { Ccabine S4 }\end{array}$ & Importado & Sem registro & $20 / 11 / 2014$ & 5 & $\mathrm{R} \$ 788,68$ & $\mathrm{R} \$ 3.943,40$ \\
\hline \multirow{2}{*}{$\begin{array}{l}\text { ParaChoque Iveco } \\
\text { Tector Curs }\end{array}$} & \multirow[t]{2}{*}{ Fibracel } & \multirow[t]{2}{*}{ 26/09/2014 } & \multirow{2}{*}{\multicolumn{2}{|c|}{$13 / 03 / 2015$}} & $\mathrm{R} \$ 1.123,62$ & $\mathrm{R} \$ 1.123,62$ \\
\hline & & & & & $\mathrm{R} \$ 10.920,60$ & $\mathrm{R} \$ 18.676,79$ \\
\hline
\end{tabular}

Fonte: Registros da empresa (2016). 
Para estes itens, aplicou-se o índice de correção IGP-M acumulado desde o mês das compras efetuadas até o dia 01/06/2016, cujos custos atualizados são expostos no Quadro 2.

Quadro 2 - Itens com valores atualizados pelo índice do IGP-M

\begin{tabular}{|c|c|c|c|c|c|c|c|c|c|c|c|}
\hline Descrição & Marca & $\begin{array}{c}\text { Data última } \\
\text { renda }\end{array}$ & $\begin{array}{c}\text { Data última } \\
\text { compra }\end{array}$ & Qtde & Custo & Total & $\begin{array}{l}\text { Preço de } \\
\text { venda }\end{array}$ & $\begin{array}{c}\text { IGP-M } \\
\text { acumulado }\end{array}$ & \begin{tabular}{|c|} 
Data \\
atualização \\
valor
\end{tabular} & $\begin{array}{c}\text { Valor } \\
\text { atualizado } \\
\text { unitário }\end{array}$ & \begin{tabular}{|c|} 
Valor \\
atualizado dos \\
itens \\
\end{tabular} \\
\hline \begin{tabular}{|c|} 
Radiador água P94 \\
P114 P124 \\
\end{tabular} & Pacini & Sem registro & 02/04/2013 & 1 & RS $1.150,00$ & RS $1.150,00$ & RS $2.300,00$ & 1,2490499 & 01/06/2016 & RS $1.436,41$ & RS $1.436,41$ \\
\hline $\begin{array}{c}\text { Atuador } \\
\text { embreagem Axor }\end{array}$ & Incoparts & Sem registro & 20/05/2013 & 1 & RS 796,49 & RS 796,49 & RS 389,00 & 1,2472414 & 01/06/2016 & RS 993,42 & RS 993,42 \\
\hline $\begin{array}{c}\text { Grade frontal Iveco } \\
\text { Eurotech }\end{array}$ & Importado & Sem registro & $18 / 09 / 2013$ & 1 & $\$ 35,00$ & $\$ 835,00$ & RS $1.670,00$ & 1,2225723 & 01/06/2016 & RS $1.020,85$ & RS $1.020,85$ \\
\hline \begin{tabular}{|c|} 
Radiador agua CLP \\
S4 S5 \\
\end{tabular} & Pacini & $11 / 07 / 2014$ & 07/07/2014 & 2 & RS $1.137,25$ & RS $2.274,50$ & RS $2.100,00$ & 1,1665368 & 01/06/2016 & RS $1.326,64$ & RS $2.653,29$ \\
\hline Porta LE FH & Importado & $26 / 05 / 2015$ & $15 / 07 / 2014$ & 2 & RS $1.350,00$ & RS $2.700,00$ & RS $2.700,00$ & 1,1683823 & $01 / 06 / 2016$ & RS $1.577,32$ & RS $3.154,63$ \\
\hline $\begin{array}{c}\text { Porta LD Eurotech } \\
\text { Eurocargo } \mathrm{S}\end{array}$ & Amalca & Sem registro & 01/09/2014 & 1 & RS $1.150,99$ & RS $1.150,99$ & RS $2.450,00$ & 1,1754776 & 01/06/2016 & RS $1.352,96$ & RS $1.352,96$ \\
\hline Catalizador 114124 & Importado & Sem registro & \begin{tabular}{|l|}
$07 / 10 / 2014$ \\
\end{tabular} & 4 & RS 704,74 & RS 2.818,96 & RS $1.554,00$ & 1,1724974 & $01 / 06 / 2016$ & RS 826,31 & RS $3.305,22$ \\
\hline $\begin{array}{c}\begin{array}{c}\text { Semi eixo LD Iveco } \\
\text { Eurotech }\end{array} \\
\end{array}$ & Resipeças & Sem registro & $14 / 10 / 2014$ & 1 & RS 721,71 & RS 721,71 & RS $1.370,00$ & 1,1717577 & 01/06/2016 & RS 845,67 & RS 845,67 \\
\hline Porta LE Volvo FM & Importado & Sem registro & $20 / 11 / 2014$ & 1 & RS $1.162,12$ & RS $1.162,12$ & RS $3.250,00$ & 1,1626653 & $01 / 06 / 2016$ & RS $1.351,16$ & RS $1.351,16$ \\
\hline $\begin{array}{c}\text { Suporte aluminio } \\
\text { LE Ccabine S4 } \\
\end{array}$ & Importado & Sem registro & $20 / 11 / 2014$ & 5 & RS 788,68 & RS 3.943,40 & RS $1.389,00$ & 1,1626653 & 01/06/2016 & RS 916,97 & RS $4.584,85$ \\
\hline $\begin{array}{c}\text { ParaChoque Iveco } \\
\text { Tector Curs } \\
\end{array}$ & Fibracel & $26 / 09 / 2014$ & $13 / 03 / 2015$ & 1 & 3,62 & RS $1.123,62$ & Rs $2.190,00$ & 1,1353215 & 01/06/2016 & 75,67 & RS $1.275,67$ \\
\hline & & & & & RS $10.920,60$ & RS $18.676,79$ & & & & RS $12.923,37$ & RS 21.974,13 \\
\hline
\end{tabular}

Fonte: Elaborado pelos autores (2016).

Por sua vez, o Quadro 3 demonstra os itens corrigidos pelo IPCA-E.

Quadro 3 - Itens corrigidos pelo índice do IPCA-E

\begin{tabular}{|c|c|c|c|c|c|c|c|c|c|c|c|}
\hline Descrição & Marca & $\begin{array}{c}\text { Data última } \\
\text { renda }\end{array}$ & $\begin{array}{l}\text { Data última } \\
\text { compra }\end{array}$ & Qtde & Custo & Total & Preço de renda & $\begin{array}{c}\text { Data } \\
\text { atualizaçào } \\
\text { ralor }\end{array}$ & $\begin{array}{c}\text { IPCA-E } \\
\text { acumulado }\end{array}$ & $\begin{array}{l}\text { Custo uni. } \\
\text { atualizado }\end{array}$ & $\begin{array}{l}\text { Custo total } \\
\text { atualizado }\end{array}$ \\
\hline \begin{tabular}{|c|} 
Radiador água P94 \\
P114 P124 \\
\end{tabular} & Pacini & Sem registro & $02 / 04 / 2013$ & 1 & RS $1.150,00$ & RS $1.150,00$ & RS $2.300,00$ & 01/06/2016 & 1,2733616 & RS $1.464,37$ & $\$ 1.464,37$ \\
\hline \begin{tabular}{|c|} 
Atuador embreagem \\
Axor Actros
\end{tabular} & Incoparts & Sem registro & 20/05/2013 & 1 & RS 796,49 & RS 796,49 & RS 389,00 & 01/06/2016 & 1,2636356 & RS $1.006,47$ & RS 1.006,47 \\
\hline $\begin{array}{c}\text { Grade frontal Iveco } \\
\text { Eurotech } \\
\end{array}$ & Importado & Sem registro & $18 / 09 / 2013$ & 1 & RS 835,00 & RS 835,00 & RS $1.670,00$ & 01/06/2016 & 1,2518647 & RS $1.045,31$ & RS $1.045,31$ \\
\hline Radiador agua CLP S4 & acini & 7/2014 & $07 / 07 / 2014$ & 2 & $1.137,25$ & $2.274,50$ & $2.100,00$ & /06/2016 & 1806006 & RS $1.342,64$ & $252.685,28$ \\
\hline Porta LE FH & Importado & $05 / 2015$ & $15 / 07 / 2014$ & 2 & RS $1.350,00$ & RS $2.700,00$ & RS $2.700,00$ & $01 / 06 / 2016$ & 1,1800834 & $\begin{array}{l}\text { RS } 1.593,11 \\
\end{array}$ & RS3.186,23 \\
\hline $\begin{array}{c}\text { Porta LD Eurotech } \\
\text { Eurocargo } \mathrm{S} \\
\end{array}$ & Amalca & Sem registro & 01/09/2014 & 1 & RS $1.150,99$ & RS $1.150,99$ & RS $2.450,00$ & 01/06/2016 & 1,177336 & RS $1.355,10$ & RS $1.355,10$ \\
\hline Catalizador 114124 & Importado & stro & \begin{tabular}{|l|}
$07 / 10 / 2014$ \\
\end{tabular} & 4 & RS 704,74 & RS 2.818,96 & 4,00 & $01 / 06 / 2016$ & 1,1716779 & $\$ 825,73$ & RS 3.302,91 \\
\hline $\begin{array}{c}\text { Semi eixo LD Iveco } \\
\text { Eurotech }\end{array}$ & Resipeças & Sem registro & 14/10/2014 & 1 & RS 721,71 & RS 721,71 & RS $1.370,00$ & 01/06/2016 & 1,1704128 & RS 844,70 & RS $\$ 44,70$ \\
\hline \begin{tabular}{|l} 
Porta LE Volvo FM \\
\end{tabular} & Importado & Sem registro & $20 / 11 / 2014$ & 1 & RS $1.162,12$ & RS $1.162,12$ & RS $3.250,00$ & 01/06/2016 & 1,1643615 & RS $1.353,13$ & RS $1.353,13$ \\
\hline \begin{tabular}{|c|} 
Suporte aluminio LE \\
Ccabine S4 \\
\end{tabular} & Importado & Sem registro & 20/11/2014 & 5 & RS 788,68 & RS $3.943,40$ & RS $1.389,00$ & 01/06/2016 & 1,1643615 & RS 918,31 & RS $4.591,54$ \\
\hline $\begin{array}{c}\text { ParaChoque Iveco } \\
\text { Tector Curs } \\
\end{array}$ & Fibracel & 26/09/2014 & $13 / 03 / 2015$ & 1 & RS 1.123,62 & RS $1.123,62$ & RS2.190,00 & 01/06/2016 & 1,1230926 & RS $1.261,93$ & RS $1.261,93$ \\
\hline & & & & & RS $10.920,60$ & RS 18.676,79 & & & & RS $13.010,79$ & RS $22.096,96$ \\
\hline
\end{tabular}

Fonte: Elaborado pelos autores (2016).

Existe uma variação no total dos produtos de $0,56 \%$ entre os índices de correção IGPM E IPCA-E conforme demonstra o Quadro 4. 
Quadro 4 - Variação de percentual entre o IGP-M e o IPCA-E

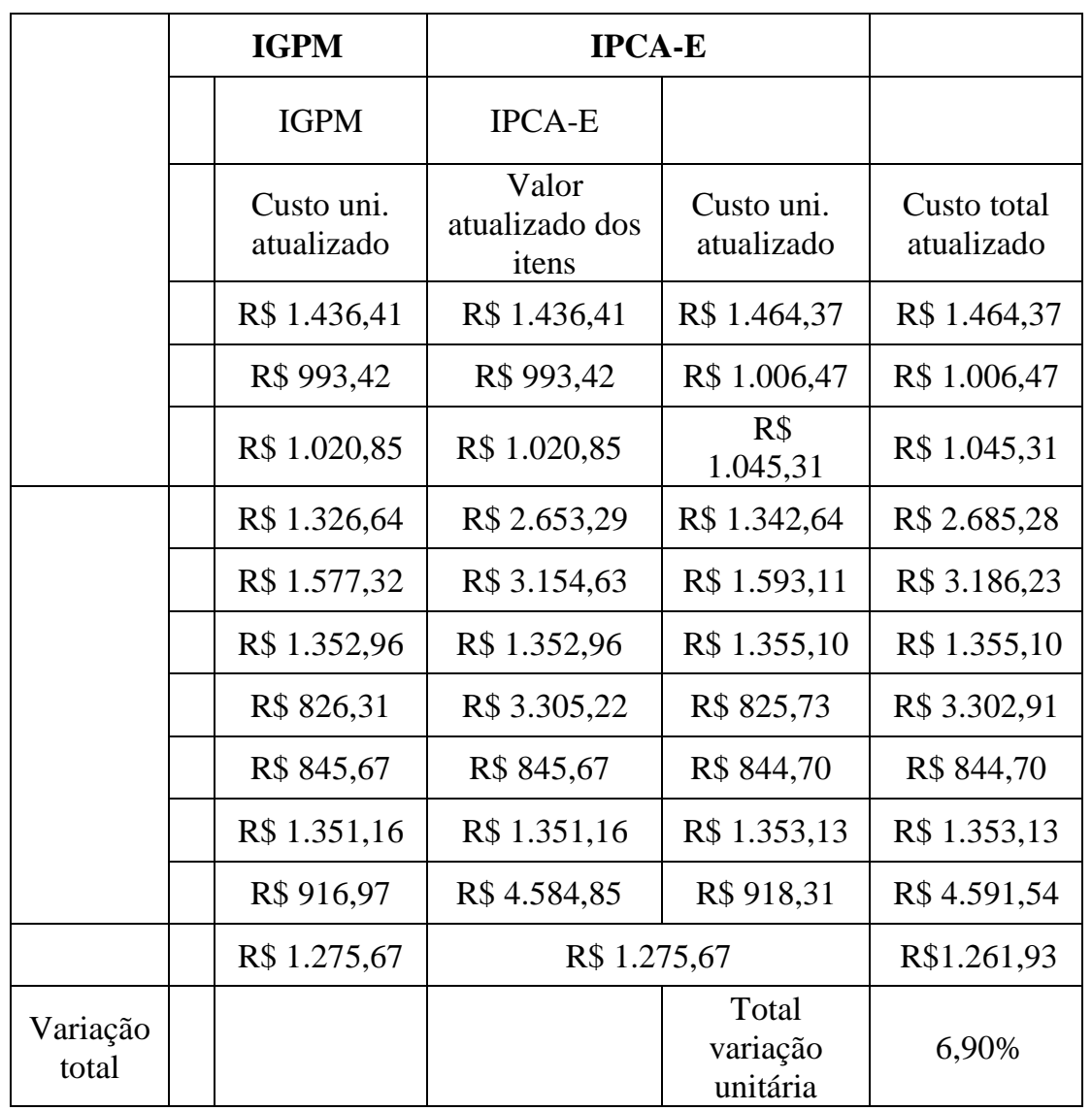

Fonte: Elaborado pelos autores (2016).

Se o valor dos 11 (onze) itens tivesse sido aplicado em um investimento CDB-DI de longo prazo o retorno final em 31/12/2015 aplicado a um índice acumulado de 1,35569052 seria de $\mathrm{R} \$ 25.319,95$, cujo valor confrontado com o preço de custo gera diferenças entre os valores, conforme demonstra a Figura 1. 
Figura 1 - Comparativo entre o custo e o valor atualizado se fosse aplicado em um investimento

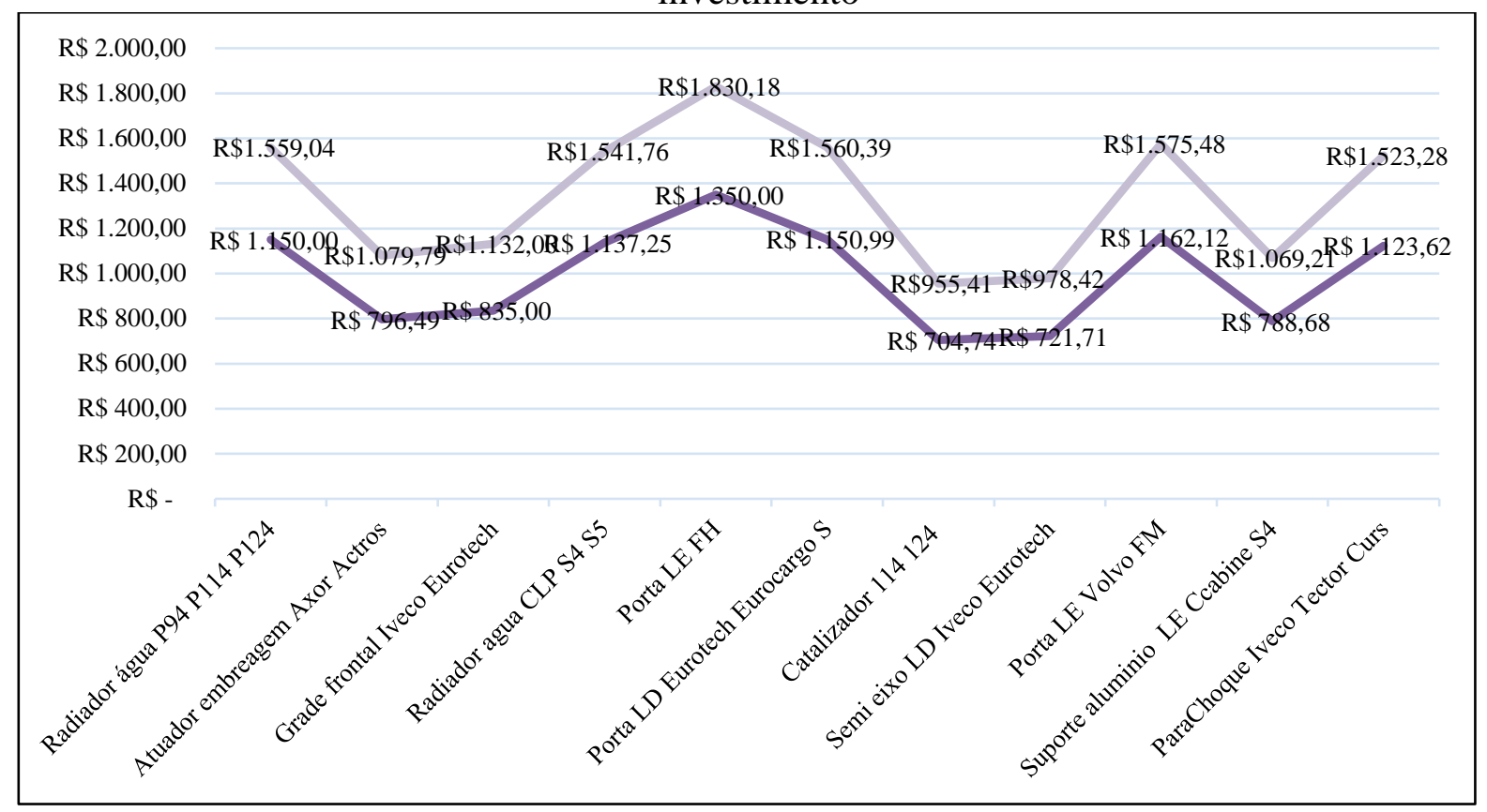

Fonte: Elaborado pelos autores (2016).

Entretanto analisando os itens que são de origem importada pelo dólar da data da compra e o dólar na data da atualização (01/06/2016) encontrou-se uma variação de 72,13\% a mais em relação do dólar da época da compra. O Quadro 5 demonstra esta comparação.

Quadro 5 - Valor atualizado pelo dólar

\begin{tabular}{|c|c|c|c|c|c|c|c|c|c|c|c|c|}
\hline Descrição & Qtde & Custo & Total & $\begin{array}{l}\text { Preço de } \\
\text { renda }\end{array}$ & $\begin{array}{c}\text { Dólar dia } \\
\text { compra }\end{array}$ & \multicolumn{2}{|c|}{$\begin{array}{c}\text { Custo em } \\
\text { dólar } \\
\text { (quantidade) }\end{array}$} & $\begin{array}{c}\text { Total em } \\
\text { dolar }\end{array}$ & $\left|\begin{array}{l}\text { Dólar em } \\
01 / 06 / 16\end{array}\right|$ & \begin{tabular}{|c|}
$\begin{array}{c}\text { Valor de custo } \\
\text { uni. atualizado } \\
\text { pelo dólar }\end{array}$ \\
\end{tabular} & $\begin{array}{l}\text { Valor total } \\
\text { atualizado }\end{array}$ & $\begin{array}{c}\text { Variação } \\
\%\end{array}$ \\
\hline $\begin{array}{c}\text { Radiador água P94 P114 } \\
\text { P124 } \\
\end{array}$ & 1 & RS $1.150,00$ & $\mid$ RS $1.150,00 \mid$ & RS $2.300,00$ & & & & & & & & \\
\hline $\begin{array}{c}\text { Atuador embreagem Axor } \\
\text { Actros }\end{array}$ & 1 & RS 796,49 & RS 796,49 & RS 389,00 & & & & & & & & \\
\hline $\begin{array}{l}\text { Grade frontal Iveco } \\
\text { Eurotech }\end{array}$ & 1 & RS 835,00 & RS 835,00 & RS $1.670,00$ & $\$ 3,032$ & $s$ & 375,12 & S 375,12 & S $\quad 3,59$ & $\$ 1.345,89$ & $\$ 1.345,89$ & $72,13 \%$ \\
\hline Radiador agua CLP S4 S5 & 2 & RS $1.137,25$ & RS $2.274,50$ & RS $2.100,00$ & & & & & & & & \\
\hline Porta LE FH & 2 & RS $1.350,00$ & RS $2.700,00$ & RS $2.700,00$ & $\$ 2,198$ & $s$ & 523,77 & $\$ 1.047,54$ & $\begin{array}{|ll|}\text { S } & 3,59 \\
\end{array}$ & $\$ 1.879,24$ & $\$ 3.758,49$ & $72,13 \%$ \\
\hline $\begin{array}{c}\text { Porta LD Eurotech } \\
\text { Eurocargo S }\end{array}$ & 1 & RS $1.150,99$ & RS $1.150,99$ & RS $2.450,00$ & & & & & & & & \\
\hline Catalizador 114124 & 4 & RS 704,74 & RS 2.818,96 & RS $1.554,00$ & $\$ 2,462$ & $s$ & 293,10 & $\$ 1.172,42$ & $\begin{array}{|ll|}\text { S } & 3,59 \\
\end{array}$ & $\$ 1.051,63$ & $\$ 4.206,51$ & $72,13 \%$ \\
\hline $\begin{array}{l}\text { Semi eixo LD Iveco } \\
\text { Eurotech }\end{array}$ & 1 & RS 721,71 & RS 721,71 & RS $1.370,00$ & & & & & & & & \\
\hline Porta LE Volvo FM & 1 & RS $1.162,12$ & RS $1.162,12$ & RS $3.250,00$ & $\$ 2,614$ & s & 301,76 & S 301,76 & S 3,59 & $\$ 1.082,68$ & $\$ 1.082,68$ & $72,13 \%$ \\
\hline $\begin{array}{c}\text { Suporte aluminio LE } \\
\text { Cabine S4 }\end{array}$ & 5 & RS 788,68 & RS $3.943,40$ & RS $1.389,00$ & $\$ 2,614$ & s & 429,91 & $\$ 2.149,56$ & 3,59 & $\$ 1.542,48$ & $\$ 7.712,42$ & $72,13 \%$ \\
\hline \multirow[t]{4}{*}{$\begin{array}{c}\text { Para-choque Iveco Tector } \\
\text { Curs } \\
\end{array}$} & 1 & RS $1.123,62$ & RS $1.123,62$ & RS $2.190,00$ & & & & & & & & \\
\hline & & & & & & $s$ & $1.923,67$ & $\$ 5.046,40$ & & $\$ 6.901,93$ & $\$ 18.105,99$ & \\
\hline & & & & & & & & & \multicolumn{3}{|c|}{ Variação unitária } & $72,13 \%$ \\
\hline & & & & & & & & & \multicolumn{3}{|c|}{ Variação no total geral } & $72,13 \%$ \\
\hline
\end{tabular}

Fonte: Elaborado pelos autores (2016).

Após as correções pelos índices de atualização monetária verificou-se que estes itens para a venda deveriam ter seus custos corrigidos, tendo em vista o tempo que estão sem 
rotatividade. Ao realizar um comparativo entre o índice IGP-M e o IPCA-E obteve-se a maximização de $0,56 \%$ no valor total dos itens pelos dois métodos. Neste caso o correto seria aplicar a correção pelo IPCA-E por apresentar maior vantagem, refletindo em um aumento de $15 \%$ em relação ao custo total dos itens coletado inicialmente.

Outra analise realizada consistiu na correção do valor do custo de aquisição total dos itens, pelo investimento CDB-DI de longo prazo cujo índice acumulado foi de 1,35569052 com um retorno final em 31/12/2015 seria de 26,24\% a mais de lucro, isto é um valor de custo de $\mathrm{R} \$ 18.676,79$ para um lucro de R\$ 25.319,95 apenas para estes 11 itens escolhidos. Para os itens que possuem origem importada, aplicou-se uma correção pelo custo do produto corrigido pelo dólar do dia 01/06/2016. Assim, percebeu-se que pelo valor neste momento econômico ser superior ao negociado na época das compras, ou seja, não seria um negócio vantajoso, levando em consideração todas as despesas que incidem para uma importação, assim sendo não haveria uma competitividade no preço dos itens em relação aos adquiridos no mercado nacional.

Por fim, sugere-se que a empresa procure realizar as vendas destes itens que estão obsoletos pelo preço do custo inicial atualizado pelo IPCA-E. Todavia, reconhece-se a incidência de perdas pelo tempo sem giro, entretanto o empresário poderá recuperar parte do que investiu elevando a receita da empresa, considerando o mercado existente para essas peças. A adoção de promoções e liquidações dá dicas como liquidar Além de simplesmente baixar os preços, busque criar promoções que induzam o cliente a comprar mais de uma peça, também configura-se como uma estratégia para a venda destes produtos (MACHADO; NUCCI, 2016).

\section{CONSIDERAÇÕES FINAIS}

A partir da concretização deste estudo, constatou-se que é necessário que o empresário faça um planejamento estratégico das compras do estoque (CREPALDI, 2009) o principal objetivo da contabilidade gerencial é fornecer informações para um correto planejamento estratégico assim auxiliando a organização na tomada de decisões indicando uma melhor forma de utilizar os recursos financeiros da empresa, e o correto controle dos insumos. O cenário financeiro da empresa deve ser analisado, antes de tomar decisões que possam acarretar em perdas de longo prazo. Assim, a realização desta pesquisa, foi válida, uma vez que seu objetivo geral foi alcançado. Constatou-se, que as compras efetuadas sem necessidade apenas para abastecer o estoque os itens foram desenfreadas e acarretaram sérios prejuízos a empresa. Para que esses altos estoques não ocorram mais é sugerido que a empresa trabalhe com estoque mínimo e efetue uma análise de mercado no que diz respeito às compras. 
No que se refere à acessibilidade e aceitação da empresa para a realização deste estudo não foram constatadas resistências. Todavia reconhece-se limitações acerca da impossibilidade de generalização dos resultados, haja vista as peculiaridades e características especificas da empresa objeto de estudo. A empresa, além disso, demonstrou interesse pelo resultado para verificar quais caminhos poderá traçar para recuperar estes valores que estão foram investidos através do estoque. Considerando a importância de estudar a temática custos, e os significativos resultados e benefícios que o trabalho pode trazer, observa-se que a pesquisa não finda aqui. Como recomendação de estudos futuros sugere-se que a replicação desta pesquisa em empresas do mesmo setor, bem como a realização de uma pesquisa de mercado a fim de identificar as marcas de caminhões predominantes no mercado, e analisar a suficiência dos preço de venda praticados.

\section{REFERÊNCIAS}

ALVES A.; SILVEIRA V. A.; TORTATO, U.; SILVA, W. V. Relacionamento entre Demanda e Estoque: estudo no setor de autopeças. XV Congresso Brasileiro de Custos. Anais..., 2008.

BEUREN, I. M. Evolução histórica da contabilidade de custos. Contabilidade Vista \& Revista, v. 5, n. 1, p. 61-66, 2009.

BOMFIM, E. A.; PASSARELli, J. Custos e Formação de Preços. São Paulo: IOB, 2008.

CAllado, A. A. C.; CALlADO, A. L. C. Mensuração e controle de custos: um estudo empírico em empresas agroindustriais. Sistemas \& Gestão, v. 1, n. 2, p. 132-141, 2006.

CARDOSO, R. L.; PEREIRA, C. A.; GUERREIRO, R. Perfil das pesquisas em contabilidade de custos apresentadas no ENANPAD no período de 1998 a 2003.Revista de Administração Contemporânea, v. 11, n. 3, 2007.

CHING, H. Y. Gestão de estoques na cadeia de logística integrada-supply chain. São Paulo: Atlas, 2000.

CREPALDI, S. A. Curso Básico de Contabilidade de Custos. 4. ed. São Paulo: Atlas, 2009.

DUBOIS, A.; KULPA, L.; SOUZA; L. E. Gestão de custos e formação de preços. São Paulo: Atlas, 2006.

GAVIOLI, G.; SIQUEIRA, M. C. M.; SILVA, P. H. R. Aplicação do programa 5s em um sistema de gestão de estoques de uma indústria de eletrodoméstico e seus impactos na racionalização de recursos. Unidade Berrini da FGV: Anais do SIMPOI, 2009.

GRECO, A.; GÃRTNER, G.; AREND, L. Contabilidade: teoria e prática básica. 2. ed. São Paulo: Saraiva, 2009. 
IUDICIBUS, S.; MARTINS, E.; GELBCKE, R. E. Manual de contabilidade das sociedades por ações. 7. ed. São Paulo: Atlas, 2009.

IUDICIBUS, S.; MARION, J. C.; FARIA, A. C. Introdução à Teoria da Contabilidade: para o nível de graduação. 5. ed. São Paulo: Atlas, 2009.

LEONE, G. S. G. Custos Planejamento, implantação e controle. 3 ed. São Paulo: Editora Atlas, 2008.

LIMA, M. P. Estoque: custo de oportunidade e impacto sobre os indicadores financeiros. CELCentro de Estudos em Logística-CEL-COPPEAD-UFRJ. Rio de Janeiro, RJ, 2003.

MACHADO, C. A. S.; BARBIERI, C. P.; PINZON, D.; CANDIA, E.; BERNARDES, A. F. J. Gestão de custos. Revista Maiêutica, Indaial, v. 3, n. 1, p. 47-54, 2015.

MACHADO, P.; NUCCI, J. P. Como se livrar de estoques indesejados? Pequenas Empresas \& Grandes Negócios, Globo, 2016.

MARTINS, E. Contabilidade de custos inclui o ABC. 9 ed. São Paulo: Atlas, 2006.

NEVES, S.; VICECONTI, P. Contabilidade de custos: um enfoque direto e objetivo. 7. ed. São Paulo: Frase 2003.

PAIVA, E. V.; FONSECA, F.; CORGOZINHO, P. R.; FERREIRA, R. M. Gestão de Custos. Anais do VI Congresso Brasileiro de Custos, São Paulo, 1999.

PADOVEZE, C. L. Curso Básico gerencial de custos. 2. ed. São Paulo: Cengage Learning, 2006.

RIBEIRO, O. M. Contabilidade de custos. 2. ed. São Paulo. Saraiva, 2011.

SANTOS, J. L. dos et al. Fundamentos de Contabilidade de Custos. São Paulo: Atlas, 2006.

STARK, J. A. Contabilidade de custos. 1. ed. São Paulo: Atlas, 2007.

WERNKE, R. Análise de custos e preço de venda: (ênfase em aplicações e casos nacionais). 1. ed. São Paulo: Saraiva, 2005.

YIN, R. Estudo de caso: planejamento e métodos. 5. ed. Porto Alegre: Bookman, 2015. 